\title{
Transport of pore-water oxygen with/without aeration in subsurface wastewater infiltration system
}

\author{
Siqi Wang', Yinghua Li' ${ }^{1 *}$, Haibo Li' and Lei Yang' \\ 'School of Resources and Civil Engineering, Northeastern University, Shenyang 110819, China
}

\begin{abstract}
In this study, three subsurface wastewater infiltration systems (SWISs) at different aeration were set up to study the transport of pore-water oxygen and quantify the amount of trapped gas. Bromide and dissolved oxygen were introduced into SWISs as partitioning tracer and non-partitioning tracer, respectively. A model named CXTFIT based on the convection diffusion equation was used to describe the shape of breakthrough curves for bromide and dissolved air in column experiments. In CXTFIT code, the parameter $\beta$ obtained from the bromide test ranging from 0.2940 to 0.7600 indicates that the physical nonequilibrium model was relatively suitable for dissolved air transport. Retardation factors obtained by CXTFIT code indicate $2-20 \%$ porosity filled with gas. Tracing the transport of air and determining the percentage of porosity filled with trapped gas has lain a foundation for further study on gas clogging in SWISs.
\end{abstract}

Keywords: gas-partitioning tracer, convection diffusion equation, subsurface wastewater infiltration system, dissolved air transport, gas clogging

\section{INTRODUCTION}

Subsurface wastewater infiltration systems (SWISs) are effective wastewater treatment methods due to the integrated mechanism of chemical, physical and biological reactions, as wastewater passes through the unsaturated soil in SWISs (Jiang, 2017). SWISs are widely used due to their low operation cost, easy maintenance, and low energy consumption (Li, 2017b).

Unfortunately, SWISs have the disadvantage of poor performance if clogging occurs. Clogging can be divided into four types: physical clogging (caused by suspended solids) (Yang, 2018; Alem, 2015); bioclogging (caused by accumulated biofilms) (Newcomer, 2016; Hua, 2014); chemical clogging (caused by chemical materials such as carbonate and iron oxide ) (Larroque, 2011; Weidner, 2012); and gas clogging (caused by gas bubbles) (Heilweil, 2013). Currently, researchers are devoted to the study of physical clogging, bioclogging and chemical clogging, but little is known about gas clogging. Gas bubbles can block pore throats, increasing the resistance to flow and reducing permeability (Martin, 2013). To study gas clogging, the sources and characteristics of gas in SWISs need to be understood.

The presence of gas bubbles in SWISs has been attributed to the biogenic gas and entrapped air. Previous studies have investigated biogenic gas. Nitrogen and nitrous oxide are produced by nitrification and denitrification. The impacts of influent loadings, drying-wetting cycles and carbon-nitrogen ratio on nitrous oxide emission and spatial distribution of nitrous oxide have been studied by Ying-Hua Li (Li, 2017a; $\mathrm{Li}, 2018) . \mathrm{N}_{2} \mathrm{O}$ conversion rate decreased with an increase in hydraulic loading (HL) but increased with increasing pollutant loading (PL) (Li, 2017a). A moderate carbon-nitrogen ratio leads to an increase in $\mathrm{N}_{2} \mathrm{O}$ emission rate and the $0-75 \mathrm{~cm}$ depth layer was the main contributor to $\mathrm{N}_{2} \mathrm{O}$ emissions ( $\mathrm{Li}, 2018$ ).

However, there is limited knowledge on the pathways of entrapped air transportation. Dissolved gases carried with

^Corresponding author, email: liyinghua@mail.neu.edu.cn Received 20 November 2018; accepted in revised form 25 September 2019 the influent were a major source of entrapped air bubbles. Compared to a saturated system, dissolved gases are more inclined to separate from the influent and penetrate into small pores in an unsaturated system like a SWIS. Entrapped air bubbles are no longer connected to the atmosphere, occurring in the form of small, immobilized, disconnected bubbles (Heilweil, 2013). By reducing the effective (quasisaturated) hydraulic conductivity, entrapped air bubbles impact water flow and solute and contaminant transport (Marinas, 2013). In order to research entrapped air, a gaspartitioning tracer test was introduced to distinguish between two fluid phases. The gas-partitioning tracer test was initially used to determine residual oil saturation by the petroleum industry (Tang, 1991a; Tang, 1991b). This has been applied more recently for the movement of air in the non-saturated zone and to measure air-filled porosity. Both a partitioning tracer and a non-partitioning tracer are injected simultaneously with influent and measured in effluent. A partitioning tracer, the low-solubility dissolved gas, will partition to the gas phase partially while a non-partitioning tracer stays in the liquid phase, which results in a partitioning tracer travelling at a lower velocity than a non-partitioning tracer. Common partitioning tracers are oxygen (Fry, 1996) and noble gas (e.g. helium, neon and argon) (Burnard, 2013; Reid, 2013). Common non-partitioning tracers are chloride and bromide. A series of transport experiments showed that the presence of small amounts of entrapped gas in the pore space could result in retardation factors for dissolved oxygen (Fry, 1995). The retardation factor is interpreted as the ratio of groundwater velocity to dissolved gas velocity and Fry reported retardation factors for dissolved oxygen varying from 1.0 to 8.0 (Fry, 1995). Higher retardation factors indicate more entrapped air. Heilweil used retardation factors obtained from a gas partitioning tracer to quantify entrapped gas in an infiltration experiment and indicated that $7 \%$ to more than $26 \%$ of the porosity was filled with gas (Heilweil, 2004). Vulave (2002) used dissolved $\mathrm{Kr}$ and $\mathrm{SF}_{6}$ gases to determine hydrogeological parameters. Through there were lower aqueous diffusion coefficients for $\mathrm{SF}_{6}$ than that for $\mathrm{Kr}$, both $\mathrm{Kr}$ and $\mathrm{SF}_{6}$ can be used with confidence to delineate 
and validate aquifer characteristics. It is noted that there is a special gas-partitioning tracer test referred as the 'Push-Pull' test (PPT). In the 'Push-Pull' test, a partitioning tracer and a non-partitioning tracer are injected ('pushed') into a porous media and then extracted ('pulled') in situ. Reid exploited the 'Push-Pull' test to research dissolved gas dynamics in wetland soils (Reid, 2015).

In this study, laboratory experiments were conducted, combined with numerical simulations, with the aim of achieving better understanding of the transport of dissolved air under various aeration conditions and quantifying the amount of trapped gas in SWISs. Tracing the transport of air and determining the percentage of porosity filled with trapped gas has lain the foundation for further studies on gas clogging in SWISs.

\section{MATERIALS AND METHODS}

\section{System description}

The soil column made of plexiglass was constructed (height $180 \mathrm{~cm}$ and internal diameter $29 \mathrm{~cm}$ ) and operated indoors. The $145 \mathrm{~cm}$ high substrate was built on top of $5 \mathrm{~cm}$ of gravel $(0.6-0.9 \mathrm{~cm}$, diameter). The substrate was evenly mixed with sand, slag and farmland soil at a ratio of 1:2.5:6.5. The porosity of the substrate was $55.0 \%$. The gravel at the bottom was used to support the infiltration system, evenly distribute the treated water and prevent outlet blockage. Influent from the water tank to the column was pumped with a peristaltic pump and distributed via a 2 -cm-diameter perforated water distribution pipe placed at $65 \mathrm{~cm}$ depth under the soil. The water was purified by the substrate and finally collected at the outlet. Rhizon soil solution samplers were placed at 40, 70, 100 and 130 cm depths (Fig. 1).

\section{Wastewater}

Artificial domestic wastewater was prepared with tap water including glucose, ammonium chloride, potassium nitrate, sodium nitrite and monopotassium phosphate. The parameters of the wastewater were as follows: $\mathrm{COD} 330.21 \pm 7 \mathrm{mg} / \mathrm{L}_{,} \mathrm{NO}_{3}{ }^{-} \mathrm{N}$ $3.12 \pm 0.1 \mathrm{mg} / \mathrm{L}, \mathrm{NO}_{2}^{-}-\mathrm{N} 0.40 \pm 0.004 \mathrm{mg} / \mathrm{L}_{,} \mathrm{NH}_{4}{ }^{+}-\mathrm{N} 49.08 \pm$ $0.6 \mathrm{mg} / \mathrm{L}, \mathrm{TP} 4.0 \pm 0.3 \mathrm{mg} / \mathrm{L}$. The domestic wastewater was treated in different ways to form the following 4 kinds of water:

- Degassed water (DW): The domestic wastewater was filtered through a degasification membrane. DO concentration was $2.0 \mathrm{mg} / \mathrm{L}$.

- Non-aerated water (NW): The domestic wastewater without any treatment. DO concentration was $6.0 \mathrm{mg} / \mathrm{L}$, the same as that of tap water.

- Micro-aerated water (MW): The domestic wastewater was continuously aerated by a $45 \mathrm{~L} / \mathrm{min}$ aeration pump. DO concentration was $9.1 \mathrm{mg} / \mathrm{L}$. Gas bubble content was $3.6 \%$. Gas content was measured following the method of $\mathrm{Du}$ (2016).

- Aerated water (AW): The domestic wastewater was aerated continuously by a $70 \mathrm{~L} / \mathrm{min}$ aeration pump. DO concentration was $9.2 \mathrm{mg} / \mathrm{L}$. Gas bubble content was $6.3 \%$.

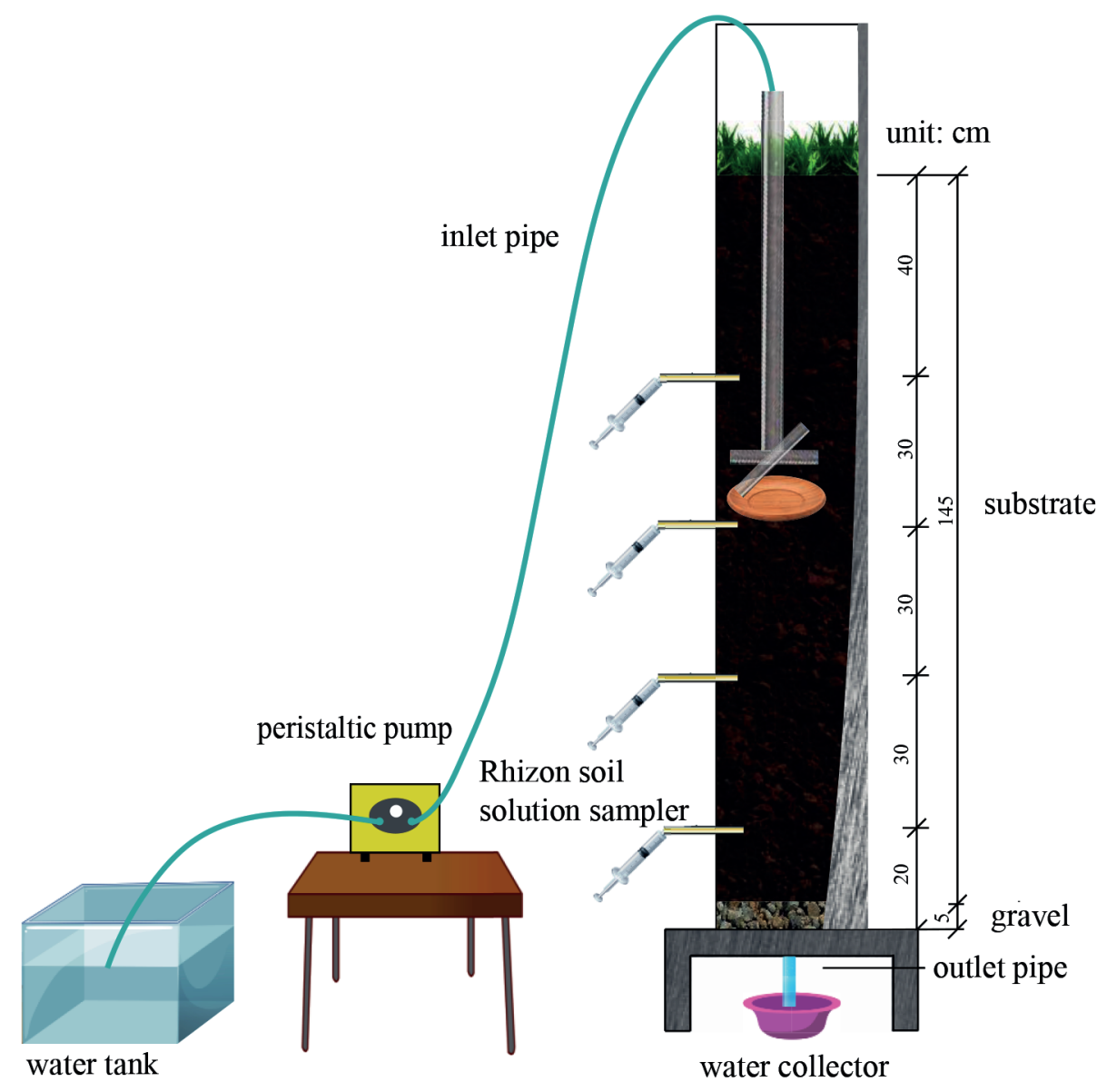

Figure 1. Diagram of SWIS and Rhizon soil solution sampler embedded in SWIS 


\section{Gas-partitioning tracer test operation}

\section{Bromide tracer test}

Phenol was added to the four types of water (DW, NW, MW and AW) as a biocide to prevent biological consumption of oxygen. Phenol concentration was $1 \%$. When the operation of the system was steady, DW was dosed in the SWIS for the first time for several days to maintain the same initial conditions. Table 1 shows measured DO concentrations after DW was injected for several days. Potassium bromide $(\mathrm{KBr})$ was added to the influent and $\mathrm{Br}^{-}$concentration was $10 \mathrm{~g} / \mathrm{L}$. The influent with $\mathrm{KBr}$ was injected for $4 \mathrm{~h}$ via a peristaltic pump. Then DW was introduced to the SWIS for the second time for about 4 days to discharge all $\mathrm{KBr}$. The hydraulic loading was $0.14 \mathrm{~m} / \mathrm{d}$. Water samples were collected at 40, 70, 100, 130 and $150 \mathrm{~cm}$ depths. $\mathrm{KBr}$ was measured to get breakthrough curves at different depths. $\mathrm{KBr}$, a non-partitioning tracer without retardation, was used to select an adaptive model and parameters for the transport of DO.

\section{Oxygen tracer test}

Instead of the influent with $\mathrm{KBr}, \mathrm{NW}, \mathrm{MW}$ and $\mathrm{AW}$ were injected for $4 \mathrm{~h}$ after dosing DW for the first time. All other experimental procedures were the same as for bromide tracer test. With the model and parameters acquired from bromide tracer test, DO concentrations were measured to get breakthrough curves at different depths and various aerations. Aeration with air was used to increase air content, i.e., increase oxygen content; the transport of DO represents the transport of air.

\section{Numerical simulations}

CXTFIT code was developed by the U.S. Salinity Laboratory. Based on the convection-dispersion equation (CDE), CXTFIT code is a model developed to estimate parameters in equilibrium and non-equilibrium transport from laboratory or field tracer experiments (Toride, 1995). CXTFIT allows for analyses of concentration distributions versus time as well as depth, and permits the use of the equilibrium and nonequilibrium transport formulations (Van Genuchten, 2012).

In CXTFIT code, the dimensionless form of equilibrium transport according to the convection-dispersion equation (CDE) is written as:

$$
R \frac{\partial C_{r}}{\partial T}=\frac{1}{P} \frac{\partial^{2} C_{r}}{\partial Z^{2}}-\frac{\partial C_{r}}{\partial Z}
$$

where $R$ is retardation factor, $C_{r}$ is the dimensionless solute concentration, $T$ is the dimensionless time, $P$ is the Peclet number, $Z$ is the dimensionless distance. The following equations define the dimensionless parameters:

$$
\begin{aligned}
& C=\frac{c}{c_{0}} \\
& P=\frac{v L}{D} \\
& Z=x / L \\
& T=\frac{v t}{L}
\end{aligned}
$$

Table 1. DO concentrations in SWIS dosed with DW

\begin{tabular}{lccccc}
\hline Depth $(\mathrm{m})$ & -0.4 & -0.7 & -1.0 & -1.3 & -1.5 \\
\hline $\mathrm{DO}(\mathrm{mg} / \mathrm{L})$ & $1.0 \pm 0.1$ & $1.0 \pm 0.1$ & $1.0 \pm 0.1$ & $1.0 \pm 0.1$ & $1.0 \pm 0.1$ \\
\hline
\end{tabular}

where $c$ is the measured concentration $(\mathrm{g} / \mathrm{L}$ or $\mathrm{mg} / \mathrm{L}), c_{0}$ is the initial concentration $(\mathrm{g} / \mathrm{L}$ or $\mathrm{mg} / \mathrm{L}), x$ is distance $(\mathrm{m}), L$ is the characteristic length $(\mathrm{m})$ representing the column length, $D$ is the dispersion coefficient $\left(\mathrm{m}^{2} / \mathrm{d}\right), t$ is time $(\mathrm{d}), v$ is the average pore-water velocity $(\mathrm{m} / \mathrm{d})$.

In CXTFIT code, the non-equilibrium transport includes chemical and physical non-equilibrium processes. The chemical non-equilibrium can be described by a two-site non-equilibrium model. The two-site non-equilibrium model divides adsorption sites into instantaneous equilibrium adsorption sites and non-equilibrium adsorption sites governed by first-order kinetics. The twosite non-equilibrium model reduced to the dimensionless form can be written as:

$$
\beta R \frac{\partial C_{1}}{\partial T}=\frac{1}{P} \frac{\partial^{2} C_{1}}{\partial Z^{2}}-\frac{\partial C_{1}}{\partial Z}-\omega\left(C_{1}-C_{2}\right)
$$

where $\beta$ is a partitioning coefficient, $\omega$ is a dimensionless mass transfer coefficient, and the subscripts 1 and 2 represent the (mobile) liquid phase and the (immobile) trapped gas phase, respectively.

The physical non-equilibrium can be described by a two-region non-equilibrium model. The two-region nonequilibrium model supposes that the liquid phase can be partitioned into mobile and immobile regions. Mass transfer between the two regions is simulated as a first-order process. The two-region non-equilibrium model reduced to the dimensionless form can be written as:

$$
(1-\beta) R \frac{\partial C_{2}}{\partial T}=\omega\left(C_{1}-C_{2}\right)
$$

In this study, the equilibrium and physical nonequilibrium model in CXTFIT code was used to simulate breakthrough and elution curves of $\mathrm{KBr}$ and DO in SWISs. CXTFIT code uses a non-linear least-square optimization approach based on the Levenberg-Marquardt method to estimate unknown parameters (Toride, 1995). $R$ is fixed as 1 due to no retardation for non-partitioning tracers such as bromide. For equilibrium transport, CXTFIT code is used to fit $D$ and $v$. For non-equilibrium transport, $v$ is the set value, CXTFIT code is used to fit $D$. Partitioning tracers have same $D$ and $v$ with non-partitioning tracers. For partitioning tracers such as oxygen, $D$ and $v$ are fixed to be the same as for non-partitioning tracers. CXTFIT code is used to fit $R$ in equilibrium transport and $R, \beta$ as well as $\omega$ in nonequilibrium transport.

\section{Sampling and analytical methods modification}

Water sampling was done at 40, 70, 100 and $130 \mathrm{~cm}$ depths via Rhizon soil solution samplers and effluent was collected at $150 \mathrm{~cm}$ depth.

Bromide was measured via the phenol red spectrophotometric method (Tomiyasu, 1996). The phenol red spectrophotometric method is suitable for low concentrations nd water samples should be diluted. DO concentrations were measured using a dissolved oxygen meter. 


\section{Method to quantify trapped gas}

Fry put forward the following equation to describe the retardation factor (Fry, 1995):

$$
R=1+H^{\prime} \frac{V_{g}}{V_{w}}
$$

where $H^{\prime}$ is dimensionless Henry's law constant, $V_{g}$ is volume of trapped gas per volume of pore space and $V_{w}$ is volume of water per volume of pore space.

With $R$ from CXTFIT code and dimensionless Henry's law constants for oxygen from Fry's research (Fry, 1995), the percentage of gas-filled porosity can be obtained by the following equation:

$$
\theta_{g}=\frac{V_{g} / V_{w}}{1+V_{g} / V_{w}}
$$

where $\theta_{g}$ is the per cent gas-filled porosity.

\section{RESULTS AND DISCUSSION}

\section{Transport of bromide}

Figure 2 shows bromide transport at different depths in SWISs. The peak measured bromide concentration reached $7.83 \mathrm{~g} / \mathrm{L}$ $\left(C / C_{0}=0.783\right)$ at $4 \mathrm{~h}(T=0.028)$ and $0.7 \mathrm{~m}$ from the surface, due to the nearby water distribution pipe placed at $0.65 \mathrm{~m}$ depth under the soil. After bromide was injected for the first $4 \mathrm{~h}$, the measured bromide concentration decreased rapidly to zero at $0.7 \mathrm{~m}$ from the surface. Under capillarity action, water travelled upward and the peak measured bromide concentration reached $1.07 \mathrm{~g} / \mathrm{L}\left(C / C_{0}=0.107\right)$ at $6 \mathrm{~h}(T=0.042)$ and $0.4 \mathrm{~m}$ from the surface. Subsequently, water moved down along the column. The time to reach peak measured bromide concentration was $12 \mathrm{~h}(T=0.085), 32 \mathrm{~h}(T=0.226)$ and $58 \mathrm{~h}(T=0.410)$ at $1.0,1.3$, $1.5 \mathrm{~m}$ from the surface, respectively. Except for $0.4 \mathrm{~m}$ from the surface, the peak measured bromide concentrations decreased with increasing depth.

The bromide tracer test not only showed the transport of non-partitioning tracer, but was also used to choose a suitable model and parameters for the transport of DO. The constraint for the chemical non-equilibrium model is that $1 / R \leq \beta \leq 0.9999$. Because $R$ is fixed as 1 in the simulation of non-partitioning tracers, the chemical non-equilibrium model is unfit for the transport of bromide. As shown in Fig.2, the equilibrium and physical non-equilibrium model were exploited to simulate bromide transport. Table 2 presents the fitted model parameters in the equilibrium and physical non-equilibrium model. Both the equilibrium and physical non-equilibrium model didn't fit bromide transport at $0.4 \mathrm{~m}$. Compared with the equilibrium model, the physical nonequilibrium model was more suitable for bromide transport due to higher $r^{2}$. In the physical non-equilibrium model, the simulation was strong and significant with $r^{2}>0.8$ at $0.7,1.0$, $1.3,1.5 \mathrm{~m}$ under the soil while it was very weak at $0.4 \mathrm{~m}$ under the soil (CXTFIT code didn't obtain a correlation coefficient). The highest dispersivity $(0.01488 \mathrm{~m})$ at $0.7 \mathrm{~m}$ under the soil was probably due to water distributed nearby, which meant much more complicated water flow conditions than other positions. The dispersivity increased from $2.712 \times 10^{-3}$ to $7.280 \times 10^{-3} \mathrm{~m}$ with depths from 1.0 to $1.5 \mathrm{~m}$ under the soil. The partitioning

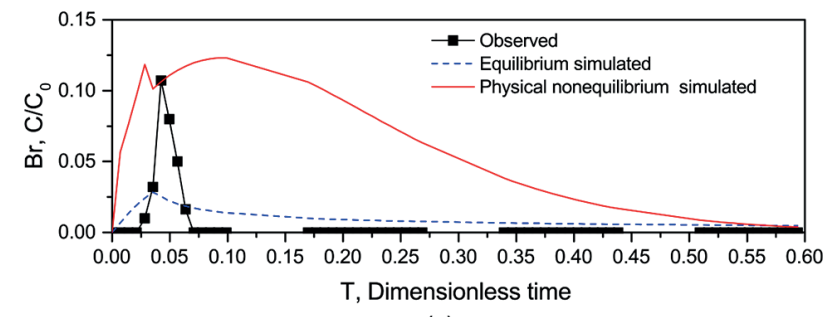

(a)

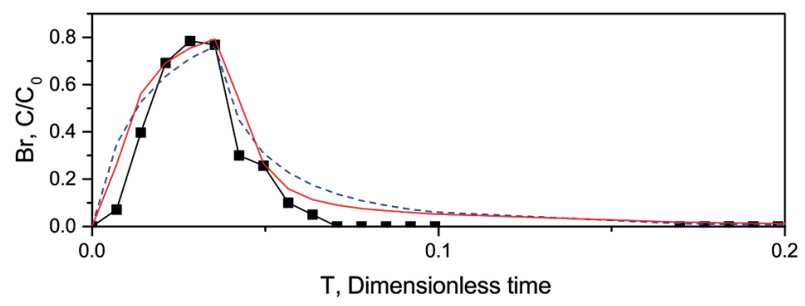

(b)

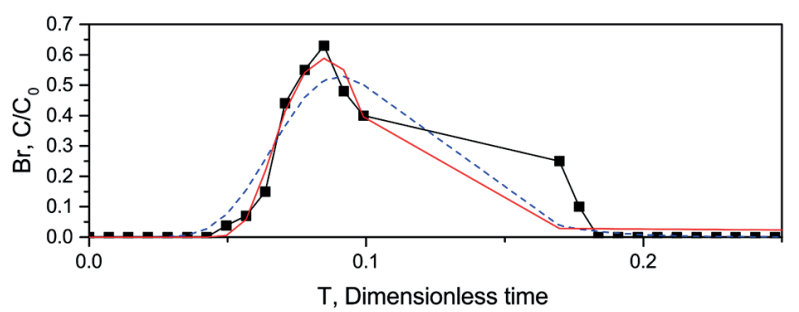

(c)

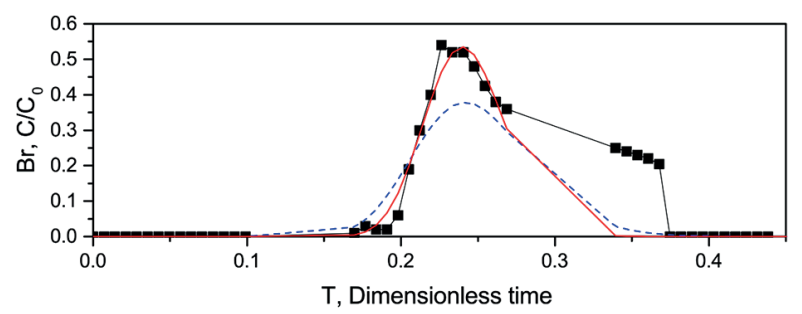

(d)

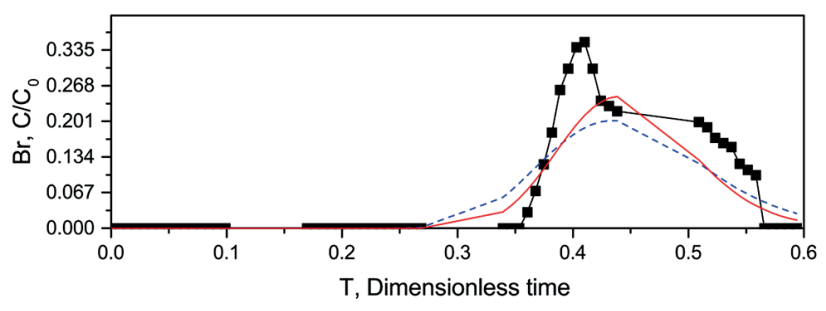

(e)

Figure 2. Observed and simulated bromide breakthrough curves at different depths. (a) $-0.4 \mathrm{~m}$ (b) $-0.7 \mathrm{~m}$ (c) $-1 \mathrm{~m}$ (d) $-1.3 \mathrm{~m}$ (e) $-1.5 \mathrm{~m}$

coefficient, $\beta$, determines the distribution of soil water between mobile and immobile regions. Through water in immobile regions doesn't move, mass exchange between mobile and immobile regions is carried out by molecular diffusion. $\beta$ ranged from 0.2940 to 0.7600 (except for $0.4 \mathrm{~m}$ under the soil), which meant that mobile regions accounted for 0.2940 to 0.7600 of the soil water and the other was immobile regions, which also had a wide range of values. A wide range of immobile regions indicates that immobile regions played an important role in bromide transport and the physical non-equilibrium 
Table 2. Fitted model parameters in bromide transport

\begin{tabular}{|c|c|c|c|c|c|c|c|c|}
\hline \multirow{2}{*}{$\begin{array}{l}\text { Depth } \\
\text { (m) }\end{array}$} & \multicolumn{4}{|c|}{ Equilibrium } & \multicolumn{4}{|c|}{ Physical non-equilibrium } \\
\hline & $\begin{array}{c}v \\
(\mathrm{~m} / \mathrm{d})\end{array}$ & $\begin{array}{c}D \\
\left(\mathrm{~m}^{2} / \mathrm{d}\right)\end{array}$ & $\begin{array}{c}\lambda \\
(\mathrm{m})\end{array}$ & $r^{2}$ & $\begin{array}{c}D \\
\left(\times 10^{-3} \mathrm{~m}^{2} / \mathrm{d}\right)\end{array}$ & $\begin{array}{c}\lambda \\
\left(\times 10^{-3} \mathrm{~m}\right)\end{array}$ & $\beta$ & $r^{2}$ \\
\hline-0.4 & 0.401 & 3.6000 & 8.978 & 0.26 & 0.50 & 1.988 & 0.0001 & - \\
\hline-0.7 & 3.83 & 0.2440 & 0.064 & 0.88 & 3.33 & 14.880 & 0.4450 & 0.91 \\
\hline-1 & 2.94 & 0.0370 & 0.013 & 0.91 & 0.68 & 2.712 & 0.2940 & 0.93 \\
\hline-1.3 & 1.88 & 0.0100 & 0.005 & 0.76 & 0.93 & 3.720 & 0.5240 & 0.82 \\
\hline-1.5 & 1.34 & 0.0103 & 0.008 & 0.75 & 1.82 & 7.280 & 0.7600 & 0.80 \\
\hline
\end{tabular}

$\lambda$ is dispersivity, $\lambda=D / v(m) ; r^{2}$ is correlation coefficient

couldn't be neglected. The asymmetric breakthrough of bromide also proved the importance of immobile regions. Therefore the physical non-equilibrium model was shown to be suitable for bromide transport. With $v$ and $D$ obtained by bromide transport in Table 2, the physical non-equilibrium was used to simulate oxygen transport.

\section{Transport of dissolved air in NW}

Figure 3 shows the transport of oxygen in NW. DO concentrations greater than $2.0 \mathrm{mg} / \mathrm{L}$ commonly refer to aerobic environments, while less than $0.2 \mathrm{mg} / \mathrm{L}$ represents anaerobic environments (Pan, 2016). DO concentration was $5.0 \mathrm{mg} / \mathrm{L}$ at $0.7 \mathrm{~m}$ under the soil, attributed to dissolved air carried by influent. DO climbed up first and then flowed down along the water's pathway. Without biological consumption of oxygen, DO could reach as deep as $1.0 \mathrm{~m}$ under the soil. All DO concentrations stabilized to be about $0.9 \mathrm{mg} / \mathrm{L}$ after $30 \mathrm{~h}$, indicating that the system with NW was under an anoxic environment. DO concentrations remained at about $0.9 \mathrm{mg} / \mathrm{L}$ at 1.3 and $1.5 \mathrm{~m}$ under the soil for the whole run, revealing that DO couldn't run through the whole column due to dissolved air partitioning to gas phase. The time of the peak measured DO concentrations was at $7 \mathrm{~h}, 6 \mathrm{~h}$, and $14 \mathrm{~h}$ at $0.4,0.7$, and $1.0 \mathrm{~m}$ under the soil. Comparing the breakthrough curves of $\mathrm{DO}$ at $0.4,0.7$ and $1.0 \mathrm{~m}$ under the soil with bromide, the time of peak measured DO concentrations was later than peak measured bromide at 0.4 , 0.7 and $1.0 \mathrm{~m}$ under the soil, which is referred to as retardation.

The simulated DO breakthrough curves and model parameters are presented in Fig.4 and Table 3, respectively.

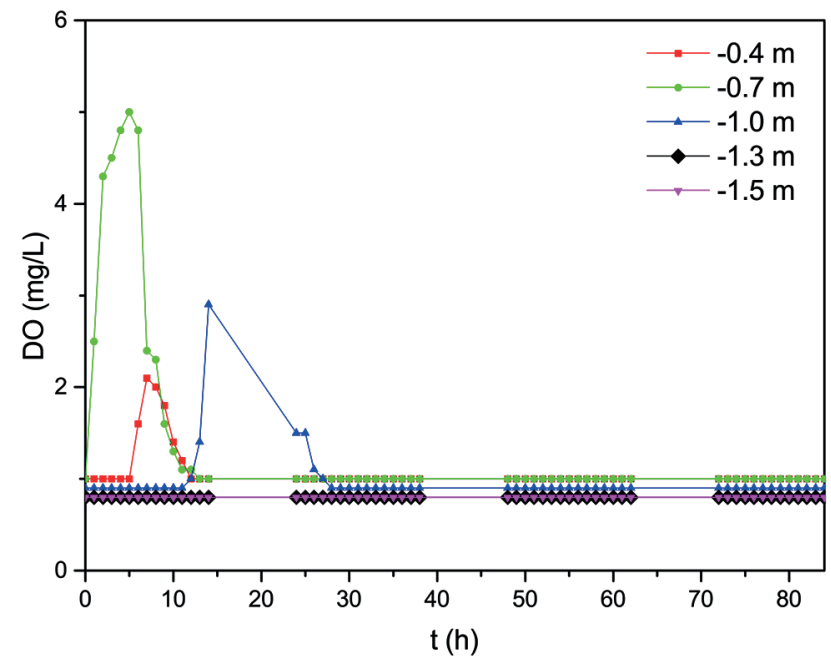

Figure 3. Breakthrough curves of DO in NW at different depths
Table 3. Fitted model parameters of DO breakthrough curves at 0.7 and $1.0 \mathrm{~m}$ under the soil in NW

\begin{tabular}{lcccc}
\hline \multirow{2}{*}{ Depth $(\mathrm{m})$} & \multicolumn{4}{c}{ Physical nonequilibrium } \\
\cline { 2 - 5 } & $R$ & $V_{\mathrm{g}} / V_{\mathrm{w}}$ & $\vartheta_{\mathrm{g}}$ & $\boldsymbol{r}^{2}$ \\
\hline-0.7 & 1.5 & 0.017 & 0.016 & 0.97 \\
-1 & 7.8 & 0.224 & 0.183 & 0.83 \\
\hline
\end{tabular}

Retardation factors ranged from 1.5-7.8 indicating 1.6-18.3\% pore space was filled with gas. $1.6-18.3 \%$ of the pore space was filled with gas, mainly occurring at $0.65-1.0 \mathrm{~m}$ under the soil. DO couldn't run through the whole column, so $R$ at $-1.3 \mathrm{~m}$ and $-1.5 \mathrm{~m}$ couldn't be obtained, thus pore space filled with gas at $-1.3 \mathrm{~m}$ and $-1.5 \mathrm{~m}$ couldn't be determined. A possible explanation for the low percentage of gas-filled porosity at $0.7 \mathrm{~m}$ under the soil is that the influent was distributed nearby and drove away the gas. With water moving down along the column, the dissolved air in water would gradually partition to the gas phase, resulting in higher gas-filled porosity at a deeper position.

In oxygen tracer tests, $C$ and $C_{0}$ was obtained by measured values minus the background values in Table 1.
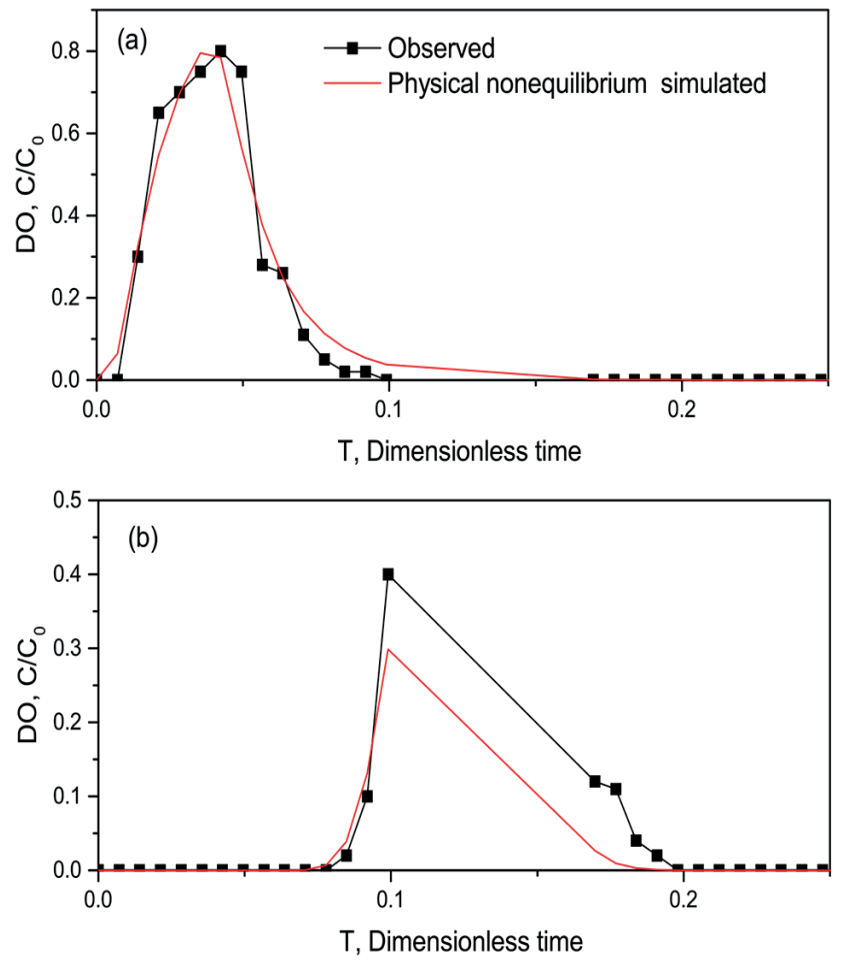

Figure 4. Observed and simulated DO breakthrough curves at 0.7 and $1.0 \mathrm{~m}$ under the soil in NW (a) $-0.7 \mathrm{~m}$ (b) $-1.0 \mathrm{~m}$ 


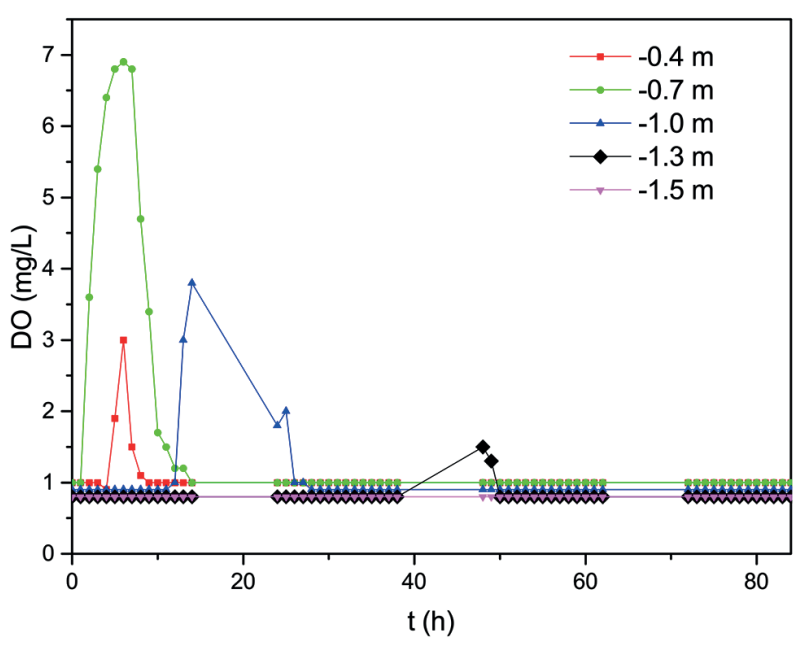

Figure 5. Breakthrough curves of DO in MW at different depths

\section{Transport of dissolved air in MW}

Breakthrough curves of DO in MW at different depths are shown in Fig. 5. The peak measured DO concentrations in MW were higher than NW at all depths. The low DO concentrations were measured at $48-49 \mathrm{~h}$ and $1.3 \mathrm{~m}$ under the soil. That deeper DO reach position can be explained by higher initial DO concentrations due to aeration.

The simulated DO breakthrough curves and model parameters are presented in Fig. 6 and Table 4, respectively. Although DO concentrations were measured at $1.3 \mathrm{~m}$ under the soil, the measured values were too few to obtain a simulated curve. Retardation factors ranging from 1.4-8.1 indicate 1.3-23.4\% pore space filled with gas.

\section{Transport of dissolved air in AW}

Breakthrough curves of DO in AW at different depths are shown in Fig. 7. Compared to the breakthrough curves of DO in NW, MW and AW, breakthrough curves showed a similar shape and tendency. Both peak measured DO concentrations in MW and AW were much higher than in NW, mirroring that aeration improved the aerobic and anaerobic conditions in the substrate. The peak measured DO concentration at $0.7 \mathrm{~m}$ under the soil in AW was almost the same as in MW. But the peak measured DO concentration at $1.0 \mathrm{~m}$ under the soil in AW was a little higher than in MW, which is probably due to the higher gas content in AW than in MW. DO concentrations in MW and AW were both measured at $1.3 \mathrm{~m}$ under the soil, reflecting that higher DO concentrations could cause deeper breakthrough positions.

The simulated DO breakthrough curves and model parameters are presented in Fig. 8 and Table 5, respectively. Simulations of NW, MW and AW produce better model fitting at $0.7 \mathrm{~m}$ under the soil and relatively worse fitting at $1.0 \mathrm{~m}$ under the soil. This is probably because water climbing to $0.4 \mathrm{~m}$ under the soil moved down to $1.0 \mathrm{~m}$ under the soil and affected the simulation effect. At $0.7 \mathrm{~m}$ under the soil, the measured DO concentrations were relatively high and water climbing to $0.4 \mathrm{~m}$ under the soil had little effect. Retardation factors indicate 1.9$17.1 \%$ of porosity filled with gas. Retardation factors remained similar at various aerations. Two possible causes can explain this phenomenon: (i) When gases in dissolved air (e.g. nitrogen, oxygen, carbon dioxide, noble gas) partition to the gas phase, gases in the gas phase (e.g. nitrogen, nitrous oxide, methane,
Table 4. Fitted model parameters of DO breakthrough curves at 0.7 and $1.0 \mathrm{~m}$ under the soil in $\mathrm{MW}$

\begin{tabular}{lcccc}
\hline \multirow{2}{*}{ Depth $(\mathrm{m})$} & \multicolumn{4}{c}{ Physical nonequilibrium } \\
\cline { 2 - 5 } & $R$ & $V_{g} / V_{w}$ & $\vartheta_{g}$ & $r^{2}$ \\
\hline-0.7 & 1.4 & 0.013 & 0.013 & 0.98 \\
-1 & 7.9 & 0.228 & 0.185 & 0.84 \\
\hline
\end{tabular}
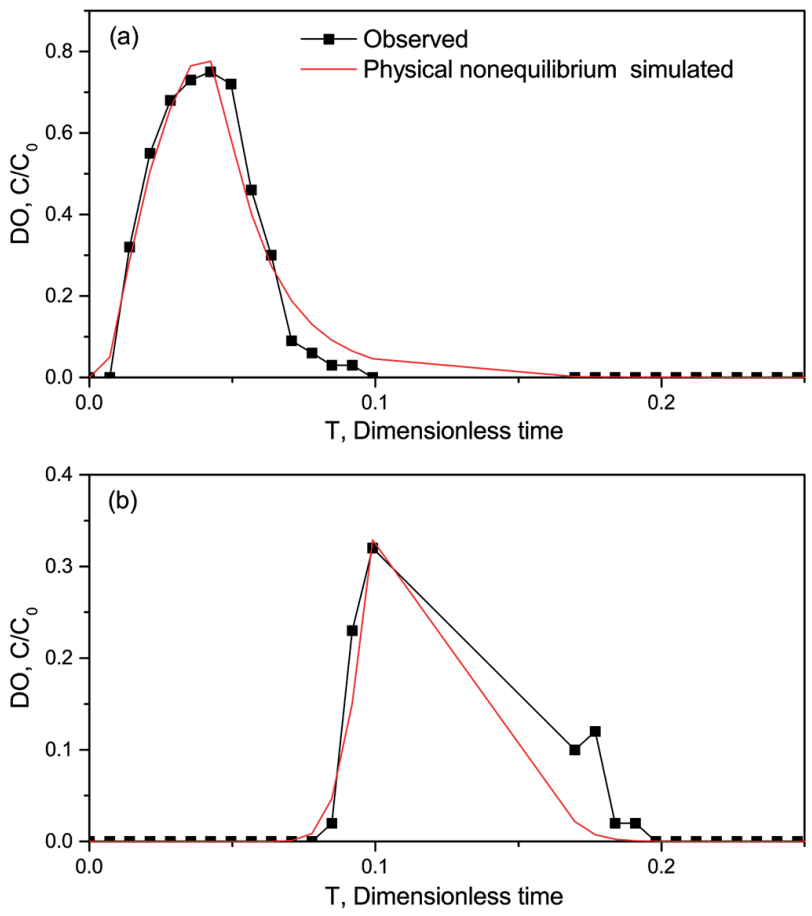

Figure 6. Observed and simulated DO breakthrough curves at 0.7 and $1.0 \mathrm{~m}$ under the soil in MW (a) $-0.7 \mathrm{~m}$ (b) $-1.0 \mathrm{~m}$

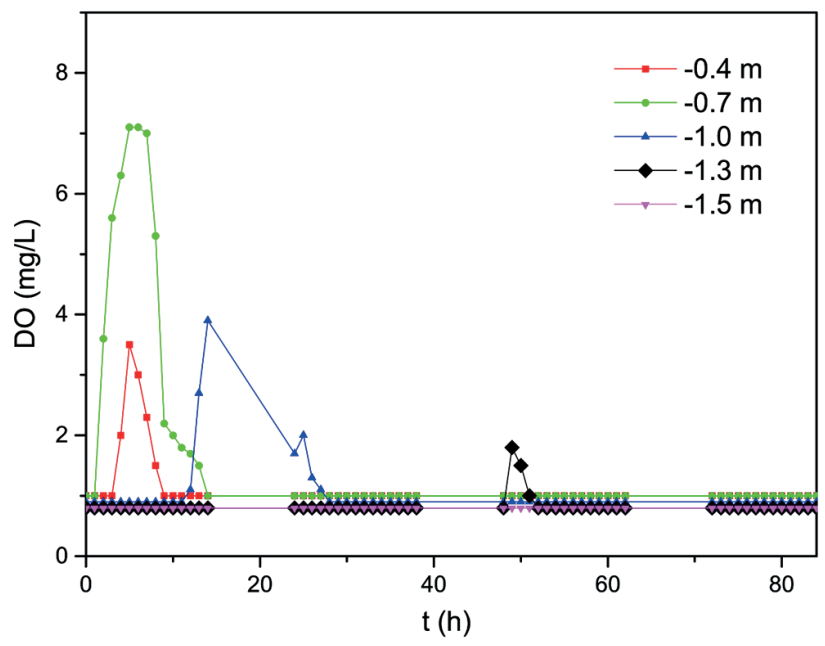

Figure 7. Breakthrough curves of DO in AW at different depths

nitrogen dioxide) partition to the liquid phase simultaneously. Gas exchange between the gas phase and the liquid phase reach equilibrium, keeping almost unchanged the percentage of porosity filled with gas. (ii) Gases in dissolved air partitioning to the gas phase move with the mobile water, resulting in a stable percentage of porosity filled with gas. 
Table 5. Fitted model parameters of DO breakthrough curves at 0.7 and $1.0 \mathrm{~m}$ under the soil in AW

\begin{tabular}{lcccc}
\hline Depth $(\mathrm{m})$ & \multicolumn{4}{c}{ Physical nonequilibrium } \\
\cline { 2 - 5 } & $R$ & $V_{g} / V_{w}$ & $\vartheta_{g}$ & $r^{2}$ \\
\hline-0.7 & 1.6 & 0.020 & 0.019 & 0.97 \\
-1 & 7.24 & 0.206 & 0.171 & 0.85 \\
\hline
\end{tabular}
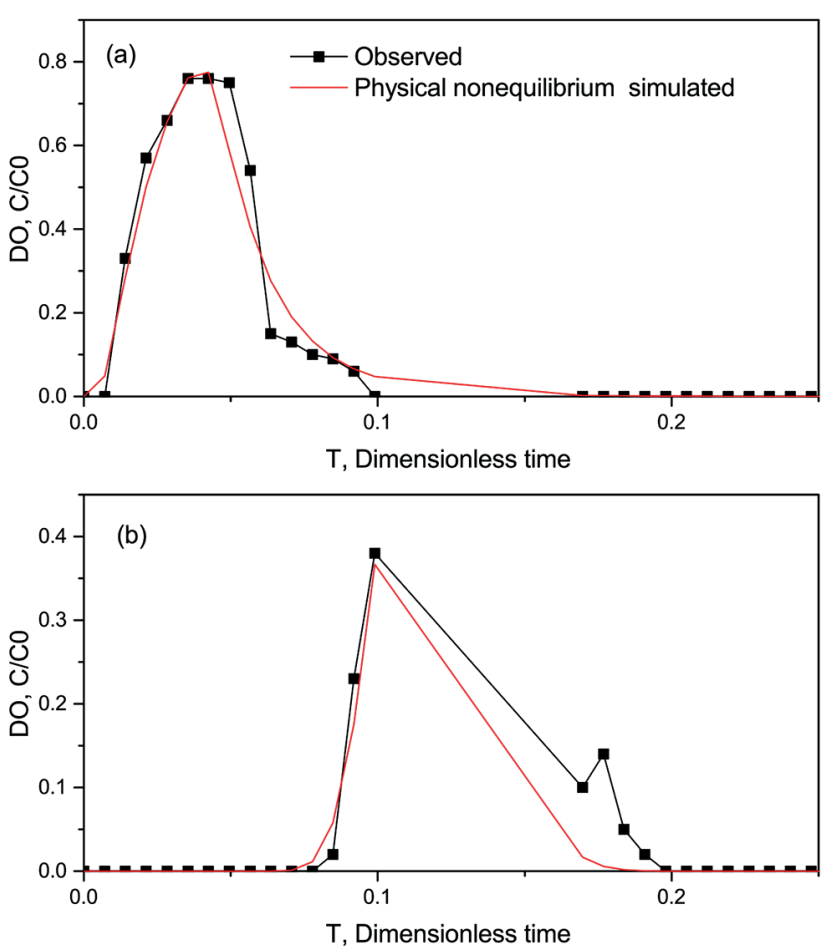

Figure 8. Observed and simulated DO breakthrough curves at 0.7 and $1.0 \mathrm{~m}$ under the soil in AW (a) $-0.7 \mathrm{~m}$ (b) $-1.0 \mathrm{~m}$

\section{CONCLUSIONS}

- CXTFIT code was first used to study dissolved air transport in SWISs. The parameter $\beta$, ranging from 0.2940 to 0.7600 , indicates that immobile regions crucially affect solute transport. So the physical non-equilibrium model was suitable for DO transport.

- DO breakthrough curves shows the process of oxygen transport. Only a small amount of DO climbed up with the water. Higher DO concentrations resulted in reaching deeper positions. Saturated DO could reach $1.3 \mathrm{~m}$ under the soil and couldn't travel through the whole soil column $(1.5 \mathrm{~m})$. Oxygen was added by aeration, which means dissolved oxygen transport can represent dissolved air transport.

- Retardation factors of DO indicated $2-20 \%$ of pore space was filled with gas. Different aeration had similar retardation factors at each depth, reflecting the percentage of porosity filled with gas remained almost the same at each depth in SWISs and higher DO or gas content in wastewater had little effect on the percentage of porosity filled with gas.

Dissolved air transport is the basis of gas clogging. Based on this preliminary study, gas clogging can be relieved by reducing bubble accumulation. Therefore, a substrate with good permeability can prevent gas clogging. The mechanism of gas clogging requires further investigation.

\section{ACKNOWLEDGEMENTS}

This work was financially supported by the National Natural Science Foundation of China [grant numbers 41571455, 51578115] and Basic Science Research Fund for Northeastern University [grant number 160104004].

\section{REFERENCES}

ALEM A, AHFIR ND, ELKAWAFI A and WANG H (2015) Hydraulic operating conditions and particle concentration effects on physical clogging of a porous medium. Transp. Por. Media 106 (2) 303-321. https://doi.org/10.1007/s11242-014-0402-8.

BURNARD P (2013) The Noble Gases as Geochemical Tracers. Springer, New York. 391 pp. https://doi.org/10.1007/978-3-642-28836-4

DU L (2016) Experimental study on gas phase clogging in aquifer recovery. Doctoral dissertation, Ji'nan University. (in Chinese) DOI: $10.14042 /$ j.cnki.32.1309.2017.05.013.

FRY VA, ISTOK JD, SEMPRINI L, O'REILLY KT and BUSCHECK TE (1995) Retardation of dissolved oxygen due to a trapped gas phase in porous media. Groundwater 33 (3) 391-398. https://doi. org/10.1111/j.1745-6584.1995.tb00295.x

FRY VA, ISTOK JD and O'REILLY KT (1996) Effect of trapped gas on dissolved oxygen transport-Implications for in situ bioremediation. Groundwater 34 (2) 200-210. https://doi. $\operatorname{org} / 10.1111 / \mathrm{j} .1745-6584.1996 . t b 01880 . x$

HEILWEIL VM and MARSTON T (2013) Evaluation of potential gas clogging associated with managed aquifer recharge from a spreading basin, Southwestern Utah, USA. In: Clogging Issues Associated With Managed Aquifer Recharge Methods. IAH Commission on Managing Aquifer Recharge, Australia. ISBN: 978-0-646-90852-6.

HEILWEIL VM, KIP SOLOMON D, PERKINS KS and ELLETT KM (2004) Gas-partitioning tracer test to quantify trapped gas during recharge. Groundwater 42 (4) 589-600. https://doi. org/10.1111/j.1745-6584.2004.tb02627.x

HUA G, ZENG Y, ZHAO Z, CHENG K and CHEN G (2014) Applying a resting operation to alleviate bioclogging in vertical flow constructed wetlands: an experimental lab evaluation. J. Environ. Manage. 136 47-53. https://doi.org/10.1016/j.jenvman.2014.01.030

JIANG Y, SUN Y, PAN J and ZHANG Y (2017) Use of dewatered sludge as microbial inoculum of a subsurface wastewater infiltration system: effect on start-up and pollutant removal. Water SA 43 (4) 595-601. https://doi.org/10.4314/wsa.v43i4.07

LARROQUE F and FRANCESCHI M (2011) Impact of chemical clogging on de-watering well productivity: numerical assessment. Environ. Earth Sci. 64 (1) 119-131. https://doi. org/10.1007/s12665-010-0823-9

LI YH, LI HB, XU XY, XIAO SY, WANG SQ and XU SC (2017a) Field study on $\mathrm{N}_{2} \mathrm{O}$ emission from subsurface wastewater infiltration system under variable loading rates and drying-wetting cycles. Water Sci. Technol. 76 (8) 2158-2166. https://doi.org/10.2166/wst.2017.388

LI YH, LI HB, XU XY, XIAO SY, WANG SQ and XU SC (2017b) Fate of nitrogen in subsurface infiltration system for treating secondary effluent. Water Sci. Eng. 10 (3) 217-224. https://doi.org/10.1016/j. wse.2017.10.002

LI YH, LI HB, XU XY, WANG SQ and PAN J (2018) Does carbonnitrogen ratio affect nitrous oxide emission and spatial distribution in subsurface wastewater infiltration system? Bioresour. Technol. 250 846-852. https://doi.org/10.1016/j.biortech.2017.12.024

MARINAS M, ROY JW and SMITH JE (2013) Changes in entrapped gas content and hydraulic conductivity with pressure. Groundwater 51 (1) 41-50. https://doi.org/10.1111/j.1745-6584.2012.00915.x

MARTIN R (2013) Clogging Issues Associated With Managed Aquifer Recharge Methods. IAH Commission on Managing Aquifer Recharge, Australia.8 pp. ISBN: 978-0-646-90852-6.

NEWCOMER ME, HUBBARD SS, FLECKENSTEIN JH, MAIER U, SCHMIDT C, THULLNER M, ULRICH G, FLIPO N and RUBIN 
Y (2016) Simulating bioclogging effects on dynamic riverbed permeability and infiltration. Water Resour. Res. 52 (4) 2883-2900. https://doi.org/10.1002/2015WR018351

PAN J, YUAN F, ZHANG Y, HUANG L, CHENG F, ZHENG F and LIU R (2016) Nitrogen removal in subsurface wastewater infiltration systems with and without intermittent aeration. Ecol. Eng. 94 471-477. https://doi.org/10.1016/j.ecoleng.2016.06.025

REID MC and JAFFÉ PR (2013) A push-pull test to measure root uptake of volatile chemicals from wetland soils. Environ. Sci. Technol. 47 (7) 3190-3198. https://doi.org/10.1021/es304748r

REID MC, PAL DS and JAFFÉ PR (2015) Dissolved gas dynamics in wetland soils: Root-mediated gas transfer kinetics determined via push-pull tracer tests. Water Resour. Res. 51 (9) 7343-7357. https:// doi.org/10.1002/2014WR016803

TOMIYASU T, TAGA Y, SAKAMOTO H and YONEHARA N (1996) Spectrophotometric determination of trace bromide by its catalytic effect on the tetrabase-chloramine T reaction. Anal. Chim. Acta 319 (1-2) 199-204. https://doi.org/10.1016/0003-2670(95)00490-4

TANG JS and HARKER BJ (1991a) Interwell tracer test to determine residual oil saturation in a gas-saturated reservoir, Part 1 . Theory and design. J. Can. Petrol. Technol. 30 (3) 76-85. https://doi. org/10.2118/91-03-08

TANG JS and HARKER BJ (1991b) Interwell tracer test to determine residual oil saturation in a gas-saturated reservoir, Part 2: Field applications. J. Can. Petrol. Technol. 30 (4) 34-42. https://doi. org/10.1016/0148-9062(92)93816-3

TORIDE N, LEIJ FJ and VAN GENUCHTEN MT (1995) The CXTFIT code for estimating transport parameters from laboratory or field tracer experiments. Research Report No. 137. US Salinity Laboratory, US Dept of Agriculture.

VAN GENUCHTEN MT, ŠIMUNEK J, LEIJ FJ, TORIDE N and ŠEJNA M (2012) STANMOD: Model use, calibration, and validation. Trans. ASABE 55 (4) 1355-1366. https://doi. org $/ 10.13031 / 2013.42247$

VULAVA VM, PERRY EB, ROMANEK CS and SEAMAN JC (2002). Dissolved gases as partitioning tracers for determination of hydrogeological parameters. Environ. Sci. Technol. 36 (2) 254-262. https://doi.org/10.1021/es0107024

WEIDNER C, HENKEL S, LORKE S, RÜDE TR, SCHÜTTRUMPF H and KLAUDER W (2012) Experimental modelling of chemical clogging processes in dewatering wells. Mine Water Environ. 31 (4) 242-251. https://doi.org/10.1007/s10230-012-0188-2

YANG M, LU M, BIAN H, SHENG L and HE C (2018) Effects of physical clogging on the performance of a lab-scale vertical subsurface flow constructed wetland system and simulation research. Ecol. Indic. 92 11-17. https://doi.org/10.1016/j. ecolind.2017.05.058 